\title{
Examining the construct validity of the positive coping behavioural inventory
}

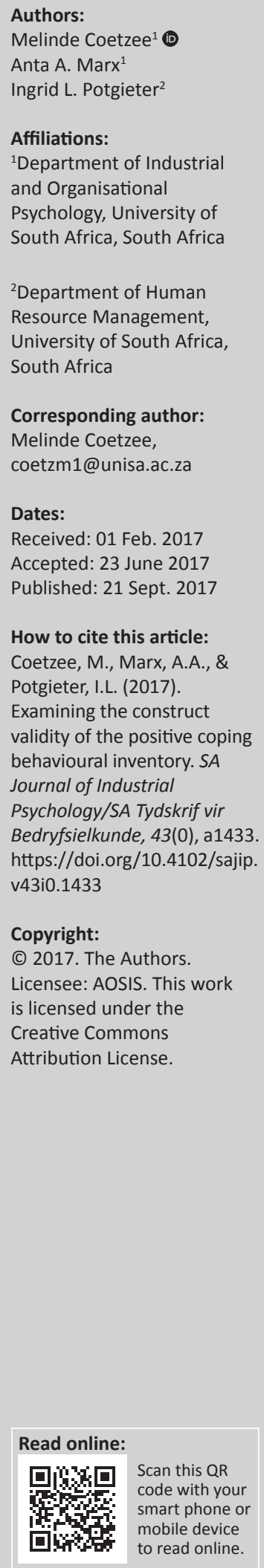

Authors:

Anta A. Marx

Affiliations:

${ }^{1}$ Department of Industrial

and Organisationa

Psychology, University of

${ }^{2}$ Department of Human

Resource Management,

University of South Africa,

Corresponding author:

Melinde Coetzee,

Dates:

Received: 01 Feb. 2017

Accepted: 23 June 2017

How to cite this article:

Coetzee, M., Marx, A.A., \&

Potgieter, I.L. (2017)

Examining the construct

behavioural inventory. SA

Journal of Industria

Psychology/SA Tydskrif vir

Licensee: AOSIS. This work

licensed under the
Orientation: Positive coping strengths are important personal resources in helping employees deal constructively with the complex interaction between the individual and the environment.

Research purpose: The present study examined the usefulness and validity of the factor structure of the positive coping behavioural inventory (PCBI) with the view to further refine the scale and increase its usefulness and application value in the South African workplace.

Motivation for the study: Valid and reliable multidimensional measures of positive psychological constructs are considered important in understanding the array of personal resources that help employees cope constructively with work-life stressors in today's fastpaced and more turbulent work environment.

Research design, approach and method: A cross-sectional survey design was utilised to collect primary data from a sample of $(N=525)$ male and female employees from white and black ethnicity origin in the services industry. The participants' self-evaluations of their positive coping behaviour were measured by means of the PCBI. Confirmatory factor analysis was performed to examine the construct validity of the PCBI.

Main findings: The convergent validity and internal consistency reliability of the PCBI as a measure of three higher-order dimensions of positive coping behaviour (inventive, engaging and intentional coping behaviours) were demonstrated in this study.

Practical and managerial implications: Researchers may confidently use the three-factor solution of the PCBI to measure employees' self-evaluations of their capacity to demonstrate positive coping behaviour in the workplace.

Contribution and value-add: This study contributed to the emerging body of knowledge on the assessment of positive psychology constructs that contribute to employees' well-being and flourishing in the South African workplace. The results provide preliminary evidence of the usefulness of the PCBI as a valid and reliable multidimensional measure that integrates a wide array of positive psychology attributes in a single measure.

\section{Introduction}

\section{Key focus}

Measures of positive psychological constructs are considered important in understanding the personal resources that help employees cope constructively with work-life stressors in today's fast-paced and more turbulent work environment (Görgens-Ekermans \& Herbert, 2013; Metzer, De Bruin \& Adams, 2014; Sims, Hogan \& Carstensen, 2015). The field of positive psychology focuses on uncovering psychosocial behavioural strengths (rather than deficits) that contribute to optimal positive human functioning (Snyder, Lopez \& Pedrotti, 2011). Positive coping strengths are important personal resources in helping employees deal constructively with the complex interaction between the individual and the work environment (Demerouti \& Bakker, 2011). Constructs relating to positive emotion (e.g. emotional intelligence, positive affect, happiness), cognition (e.g. hope, optimism, problem-solving, self-acceptance, self-esteem), intrinsic motivation (e.g. locus of control, resilience, self-efficacy, flourishing) and interpersonal interactions (e.g. extroversion, agreeableness, social support) are inherent to positive coping behaviour and seen to facilitate better adjustment to stressful life events (Hammer, 1988; Marx, 2016; Proyer, Gander, Wellenzohn \& Ruch, 2014). Measuring individuals' positive coping strengths in a valid and reliable manner has therefore become an important endeavour for scholars and practitioners as studies have shown important links between positive coping constructs and positive work and organisational outcomes such as work engagement, job satisfaction, productivity, well-being and low turnover intention (Mayer, 2014; Rothmann, 2014; Van der Heijde, 2014). The present research 
contributes to the emerging South African-based research on positive psychology in its aim to examine the construct validity of the positive coping behavioural inventory (PCBI) that was developed by Marx (2016) for the South African work context.

\section{Background to the study}

The initial theoretical development of the PCBI and an exploratory factor analysis (EFA) by Marx (2016) revealed a four-factor solution of the scale comprising constructs relating to higher-order positive cognition (inventive problem-solving), positive emotion (happy, engaging affect), intrinsic motivation (intentional self-efficacious goal-directed behaviour) and positive social behaviour (influential strengths such as extroversion and social support). The present study is the first study to further examine the construct (multidimensional) validity and internal consistency reliability of the PCBI as an extension of the preliminary research conducted by Marx (2016).

A review of the research literature revealed two core problems relating to the measurement of positive psychology constructs in the workplace. Firstly, a problem that arises is the availability of international and local measures of positive psychology constructs that can be applied with confidence in the South African workplace context. Scholars exert much energy in examining the psychometric properties, and especially the reliability and validity of internationally developed measures when applied in South African workplace settings (Görgens-Ekermans \& Herbert, 2013; Metzer et al., 2014). The Employment Equity Act (Act No. 55 of 1998) prohibits psychological testing and assessment unless the reliability and validity of the test and assessment have been scientifically proven. Examining the construct validity and reliability of the PCBI is therefore an important next step in evaluating the usefulness of the scale in assessing positive coping behaviour in a valid manner. The present study examines a multidimensional positive coping behaviour measure developed for the South African context that encapsulates constructs generally assessed by Western-based international measures. In this regard, the study also contributes to research on positive coping behaviour in the South African workplace setting.

Second, a review of the research literature on the measurement of positive psychology constructs revealed several measures that have a core construct focus such as, for example, emotional intelligence (Schutte et al., 1998), optimism (Scheier \& Carver, 1985), resilience (Wagnild \& Young, 1993), locus of control (Schepers, 2005) and self-efficacy (Parker, 1998). Measures that follow a multi-trait approach in assessing positive psychological coping behavioural strengths also emerged; for example, the psychological capital (PsyCap) scale (PCQ-24: Luthans, Avolio, Avey \& Norman, 2007) measures an array of constructs such as hope, optimism, self-efficacy and resilience which are encapsulated in a higher-order constellation of individuals' PsyCap. Ryff's (1989) scale of psychological well-being measures, for example, positive psychological constructs such as personal growth, autonomy, self-acceptance, purpose in life and personal relations, while Keyes's (2002) mental health continuum scale measures flourishing constructs such as emotional well-being, psychological well-being and social well-being. In the coping and stress realm, Hammer's (1988) coping resources inventory (CRI) assesses coping resources as cognitive (e.g. positive sense of self-worth, optimism), emotional (e.g. positive affect), social (e.g. embeddedness in social networks), spiritual and/or philosophical (e.g. values) and physical (e.g. health-promoting behaviours) predispositions that enable individuals to handle stressors more effectively. In response to these measures, Marx (2016) argues for a cost-effective multidimensional measure that integrates a wide array of constructs that are emphasised in the positive psychology field. The basic premise is that using a wide array of several scales in order to assess an individual's positive coping strengths can be a costly exercise. In this regard, scholars and practitioners continuously strive to examine the construct validity of scales with the intent to find ways of shortening a scale and to identify constructs that are most relevant and useful to the South African workplace context (Metzer et al., 2014).

\section{Research objective}

The present study contributes to the emerging positive psychology research literature by examining the reliability and validity of the factor structure identified by Marx (2016) with the view to further refine the PCBI scale and increase its usefulness and application value in the South African workplace. The PCBI is seen to fill an important gap in the research literature by offering a multidimensional measure that assesses a wide array of positive psychological constructs that have been indicated by the research literature as important positive strengths in coping with stress and improving employee well-being (Marx, 2016). Further examination of the mutidimensional psychometric properties of the scale is therefore warranted and important.

\section{Trends from the research literature}

Marx (2016) approaches positive coping behaviour from a multidimensional and psychosocial perspective. As shown in Table 1, the psychosocial dimensions of positive coping behaviour (Marx, 2016) relate to positive behavioural capacities embedded in individuals': (1) inventive coping behaviour (positive problem-solving anchored in individuals' self-esteem, internal locus of control, optimism, humour and positive reframing, emotional, motivational and interpersonal [social] capacities), (2) engaging coping behaviour (generating and maintaining positive emotions, feeling self-efficacious in alleviating stress through emotional granularity and feelings of happiness and engagement), (3) intentional coping behaviour (proactive coping through intrinsic motivational and selfefficacious goal-directed behaviour, conscientiousness, adaptability, resilience and flourishing) and (4) influential coping behaviour (positive social behaviour through extroverted behaviour, positive interactions with others, agreeableness 
TABLE 1: Four-factor constructs and definitions of the 41-item positive coping behavioural inventory.

\begin{tabular}{|c|c|c|}
\hline Sub-dimension construct & Definition & Positive coping constructs \\
\hline $\begin{array}{l}\text { Inventive coping } \\
\text { behaviour }\end{array}$ & $\begin{array}{l}\text { Positive problem-solving behaviour relates to cognitive strengths anchored in the } \\
\text { individual's self-esteem and internal locus of control. The individual is open to life } \\
\text { experiences and applies wisdom, optimism, humour and positive reframing in dealing } \\
\text { with stressful or painful life events. }\end{array}$ & $\begin{array}{l}\text { Cognitive attributes (innovative speciality), wisdom, } \\
\text { self-esteem (worthiness), optimism, humour (amusement), } \\
\text { locus of control, openness to experience (broad-minded } \\
\text { practice) and positive reframing (resolute review). }\end{array}$ \\
\hline $\begin{array}{l}\text { Engaging coping } \\
\text { behaviour }\end{array}$ & $\begin{array}{l}\text { Positive emotional behaviour relates to the capacity to generate and maintain positive } \\
\text { emotions and feelings even in difficult or stressful circumstances. The individual feels } \\
\text { self-efficacious in alleviating the stressful situation by demonstrating a happy and engaged } \\
\text { attitude towards the self, the situation and others. }\end{array}$ & $\begin{array}{l}\text { Positive affect, emotional granularity, happiness } \\
\text { (euphoria), self-efficacy. }\end{array}$ \\
\hline $\begin{array}{l}\text { Intentional coping } \\
\text { behaviour }\end{array}$ & $\begin{array}{l}\text { Positive motivational behaviour relates to the self-efficacious capacity to intentionally and } \\
\text { conscientiously engage in positive goal-directed behaviours that encompass active } \\
\text { detachment from unhealthy attachments, the deliberate achievement of optimal well-being } \\
\text { and the building of strengths and resources to adjust proactively to stressful situations. }\end{array}$ & $\begin{array}{l}\text { Self-efficacy, resilience, flourishing, intention for positive } \\
\text { health, proactive coping, conscientiousness, adaptability. }\end{array}$ \\
\hline $\begin{array}{l}\text { Influential coping } \\
\text { behaviour }\end{array}$ & $\begin{array}{l}\text { Positive social behaviour relates to extroverted behaviour that facilitates positive } \\
\text { interaction with others through positive self-other evaluations. }\end{array}$ & Extroversion, social support and agreeableness. \\
\hline $\begin{array}{l}\text { Positive coping } \\
\text { behaviour }\end{array}$ & $\begin{array}{l}\text { Positive coping behaviour denotes individuals' positive self-evaluations regarding their } \\
\text { problem-solving and cognitive strengths, self-efficacious capacity to intentionally and } \\
\text { conscientiously generate and maintain positive emotions and engage in positive goal- } \\
\text { directed and extroverted behaviour in adjusting successfully to stressful situations. }\end{array}$ & $\begin{array}{l}\text { Positive problem-solving behaviour, positive emotional } \\
\text { behaviour, positive motivational behaviour and positive } \\
\text { social behaviour. }\end{array}$ \\
\hline
\end{tabular}

and building social support). This multidimensional approach towards positive coping is in agreement with the argument that coping resources consist of a complex and dynamic set of cognitive, emotional, motivational and social (interpersonal) behavioural responses that affect the outcome of potentially stressful events (Hammer, 1988; Papastavrou et al., 2011).

Scholars engaged in positive psychology research generally argue in favour of multidimensional measures of well-being to understand positive coping behaviour (Luthans et al., 2007; Rothmann, 2014). Advantages of measures with multidimensional constructs are that they can help to capture the complexity of positive coping behaviour and well-being and help to identify the strengths and potential areas for growth that inform intervention design (Rothmann, 2014).

Flourishing theory (Keyes \& Annas, 2009; Ryff \& Keyes, 1995; Youssef \& Luthans, 2012) postulates that optimal human flourishing is characterised by growth and generativity that stem from mental health (thinking well), emotional wellbeing (feeling well) and psychological and social well-being (functioning well). Seen through the theoretical lens of flourishing theory (Keyes \& Annas, 2009; Ryff \& Keyes, 1995), it is argued that positive coping behaviour represents an array of responses flowing from a positive state of mental health and emotional, psychological and social well-being. Each state of optimal flourishing (i.e. mental, emotional, psychological, social) is supported by an array of selfregulating personal resources that affect the outcome of potential stressful events that the individual has to confront in the person-environment interaction process (Rothmann, 2014). Marx's (2016) theoretical framework and empirical measure (PCBI) organise a wide array of positive personal coping and flourishing resources into four dimensions of positive coping behaviour (i.e. inventive coping behaviour, engaging coping behaviour, influential coping behaviour and social coping behaviour). The common theme underlying these four dimensions is the link with individual mental health and emotional, psychological and social well-being as espoused in flourishing theory.

Research indicates that mental health is supported by cognitive orientations and traits such as wisdom, self- esteem, humour, internal locus of control, openness to experience and positive reframing. These positive coping constructs have been associated with well-being and creative (inventive) problem-solving behaviour (Ardelt \& Edwards, 2015; Helmer, Krämer \& Mikolajczyk, 2012; Kleiman \& Riskind, 2012; Lambert, Graham, Fincham \& Stillman, 2009; McGraw, Warren \& Kan, 2015; Ong, Phillips \& Chai, 2013). Positive emotions, emotional granularity and happiness are positively linked to adaptive coping behaviour (Serena, 2013), engagement (Sulea, van Beek, Sarbescu, Virga \& Schaufeli, 2015), mental health (Snyder et al., 2011), and well-being (De Zutter et al., 2010). Psychological well-being constructs such as self-efficacy, resilience, flourishing, intentions for positive health, proactive coping, conscientiousness and adaptability are positively associated with intrinsic motivational and intentional goal-directed behaviour and the capacity to adapt to stress and adversity (Asamani, Cobbold \& Dai-Kosi, 2015; Kim, Newton, Sachs, Glutting \& Glanz, 2012; Marx, 2017; Stratta et al., 2015; Windle, 2011; Zhao \& Seibert, 2006). Positive traits such as extroversion and agreeableness are positively linked to positive coping and the capacity to build social support (Fornés-Vives, Garcia-Banda, Frias-Navarro \& RosalesViladrich, 2015; Lucas \& Fujita, 2000; Sulea et al., 2015). The value of Marx's (2016) initial research is the integration of a wide array of positive psychology constructs that have emerged as important flourishing and well-being constructs into a higher-order four-dimensional theoretical framework and empirical measure (PCBI) of positive coping behaviour. Although the initial EFA conducted by Marx (2016) provided evidence of the four-factor structure of the postulated fourdimensional theoretical framework, further validation of the internal multidimensional structure of the PCBI is still lacking. The present study addresses this gap in research by examining the construct validity and internal consistency reliability of the PCBI.

\section{Research design Research approach}

The research followed a cross-sectional quantitative research approach. Non-probability convenience sampling was utilised to collect primary data. 


\section{Research participants}

Marx's (2016) initial EFA on the PCBI was conducted on a random sample of $N=200$ employees in a single business company in the services industry. The present study comprised a convenience sample of $N=525$ employees working in a chemical services company with a broad geographic spread. A 100\% response rate was obtained. The sample consisted of $52 \%$ male and $48 \%$ female participants and people from black (51\%) and white (49\%) ethnicity origin. The mean age of the sample was $M=37.92$ (standard deviation $=10.94$ ).

\section{Measuring instrument}

The 41-item PCBI developed by Marx (2017) was examined in terms of its structural validity in the present study. The initial EFA conducted by Marx (2017) revealed four dimensions: inventive coping behaviour (10 items, e.g. 'I believe most problems can be overcome by viewing them in a positive light'), engaging coping behaviour ( 8 items; e.g. 'I feel happy, joyful and excited most of the time'), intentional coping behaviour (18 items, e.g. 'I constantly strive to improve my ability to deal with difficult situations') and influential coping behaviour (5 items; e.g. 'I am not afraid to expose myself to risks'). A six-point Likert-type scale ( $1=$ definitely agree; 6 = definitely disagree) is utilised to capture responses. Low scores imply positive self-evaluation about the capacity to demonstrate the behaviour while high scores imply negative self-evaluation about the capacity to demonstrate the behaviour. Marx (2016) reported internal reliability coefficients above 0.79 for all four subscales.

\section{Research procedure}

Data were collected electronically by means of e-mail and by means of fieldwork (site visits) during which hard copies of the questionnaire were distributed to the participants.

\section{Ethical consideration}

The research institution granted permission for the research, and permission to conduct the study was obtained from the company management. Informed consent was obtained from the participants. Ethical considerations such as anonymity, voluntary participation and confidentiality were adhered to in the data collection process.

\section{Statistical analysis}

The SAS Version 6.1 (2013) PRO CALIS procedure was utilised to perform confirmatory factor analysis (CFA). Because of the cross-sectional nature of the research and concerns about common method bias, the first step was to calculate a one-factor CFA (all items of the PCBI loading onto one-factor) and Harman's one-factor solution on the PCBI. The one-factor solution was compared with the original fourfactor solution identified by the developer of the PCBI. The first evaluation of construct validity was therefore to assess whether the four-factor solution had a better fit with the data than the one-factor CFA model. Second, two additional competing CFA measurement models were fitted to the data in order to assess the best fit structural model for the PCBI. The following fit indices were examined in order to assess model fit: the test of close fit which tests whether the root mean square error of approximation (RMSEA) and standardised root mean square (SRMR) are less than or equal to 0.08 for indicating a reasonable model fit or less than/ equal to 0.05 for a well-fitting model together with the comparative fit index (CFI) and non-normed fit index (NNFI) obtaining cut-off values of 0.90 or higher. The Akaike Information Criterion (AIC) was also inspected to compare the various CFA models. Low AIC values are seen to indicate a reasonable fit (Hair, Black, Babin \& Anderson, 2010; Hu \& Bentler, 1999).

The path coefficients of the best fit CFA model were evaluated in order to assess the convergent validity of the structural model. A significant standardised regression estimate (path coefficient) of 0.50 and higher was used as threshold value for evidence of convergent validity (Kline, 2011). The $t$-values above 1.96 indicate path coefficient significance at $p \leq 0.05$ and $t$-values above 2.56 indicate path coefficient significance at $p \leq 0.01$ (SAS PRO Calis procedure, 2013).

Cronbach's alpha coefficients and composite reliability (CR) coefficients (a less biased estimate of reliability than Cronbach's alpha: Alarcón \& Sánchez, 2015) were used to assess the internal consistency reliability of the PCBI and to flag poor-fitting items. In line with the criterion of Fornell and Larcker (1981) and guidelines of Alarcón and Sánchez (2015), $\mathrm{CR}$ and the average variance extracted (AVE) were also inspected to assess the convergent validity of the measurement model. AVE measures the level of variance captured by a construct versus the level caused by measurement error (Alarcón \& Sánchez, 2015). AVE values above 0.70 (very good) and 0.50 (acceptable) and CR values of 0.70 and above (acceptable) were considered in the analysis to indicate acceptable convergent validity (Alarcón \& Sánchez, 2015).

\section{Results \\ Descriptive statistics and internal consistency reliability of the positive coping behavioural inventory}

The initial four-factor best fit CFA model was examined in terms of descriptive statistics in order to identify items and factors with low internal consistency reliabilities. The descriptive statistics (means and standard deviations, internal consistency reliability coefficients, AVEs) and bivariate correlations are reported in Table 2. In terms of the means, low scores imply positive self-evaluation about the capacity to demonstrate the behaviour while high scores imply negative self-evaluation about the capacity to demonstrate the behaviour (Marx, 2016). Overall, the mean scores reflected positive self-evaluations of the capacity to demonstrate positive coping behaviour. The internal consistency reliability coefficients (CRs) were all well above the threshold value of 0.70 (acceptable) with a range between 0.82 and 0.95 . The AVEs were below the threshold value of 0.50 (range: 0.37 to 0.44 ), which indicates the presence of measurement error. 
TABLE 2: Descriptive statistics: Means, standard deviations, reliability coefficients, average variance extracted and bivariate correlations.

\begin{tabular}{|c|c|c|c|c|c|c|c|c|c|c|c|}
\hline Number & Variable & Mean & $S D$ & Cronbach's alpha & Composite reliability & AVE & 1 & 2 & 3 & 4 & 5 \\
\hline 1 & Inventive coping behaviour & 2.33 & 0.81 & 0.78 & 0.82 & 0.44 & - & - & - & - & - \\
\hline 2 & Engaging coping behaviour & 2.55 & 0.92 & 0.87 & 0.86 & 0.37 & $0.78^{*}$ & - & - & - & - \\
\hline 3 & Intentional coping behaviour & 2.35 & 0.81 & 0.93 & 0.93 & 0.41 & $0.77^{*}$ & $0.77 *$ & - & - & - \\
\hline 4 & Influential coping behaviour & 2.59 & 0.96 & 0.79 & 0.80 & 0.44 & $0.63^{*}$ & $0.63^{*}$ & $0.72 *$ & - & - \\
\hline 5 & $\begin{array}{l}\text { Overall positive coping } \\
\text { behavioural inventory }\end{array}$ & 2.42 & 0.78 & 0.96 & 0.95 & 0.42 & $0.87^{*}$ & $0.89 *$ & $0.96 *$ & $0.80 *$ & - \\
\hline
\end{tabular}

SD, standard deviation; AVE, average variance extracted.

$N=525$.

$*, p \leq 0.001$

The bivariate correlations among the four subfactors were all positive and significant $(r \geq 0.63$ to $r \leq 0.78 ; p=0.0001$; large practical effect). All four factors correlated positively and significantly with the overall PCBI construct $(r \geq 0.87$ to $r \leq$ 0.96; $p=0.0001$; large practical effect).

\section{Construct validity of the positive coping behavioural inventory}

The first step was to test for potential common method bias because of the cross-sectional nature of the research design and the subjective self-report approach of the PCBI. The Harman's one-factor solution for the PCBI showed that loading the original 41 items onto one overall construct accounted for only $17.69 \%$ of the covariance among the scale variables. The one-factor CFA solution (all items of the PCBI loading onto one-factor) had poor data fit with CFI and NNFI values below 0.80 (see Table 3 ). These results suggested that common method bias did not pose a serious threat to the findings.

The CFA one-factor model was compared with a four-factor CFA model based on the original 41-item PCBI. As reported in Table 3, the original four-factor solution had less than acceptable data fit with the CFI and NNFI values being lower than the threshold value of $0.90(\mathrm{CFI}=0.88$ and NNFI $=0.87)$. However, the four-factor solution (all items loading onto the respective subfactor, and the four factors loading onto the overall PCBI construct) had better model fit than the onefactor CFA solution with a lower AIC value and improvement in the RMSEA (0.06) and SRMR (0.05) values which indicated reasonable fit. These results provided initial evidence of internal construct (convergent and discriminant) validity of the four-factor PCBI.

Model modification of the four-factor model was then done in order to improve the CFI and NNFI fit indices. This step involved removing two problematic items (path coefficients below 0.50) from the inventive coping behaviour subscale. This step reduced the original 41 items to 39 items. Table 3 shows that the modified four-factor solution had only a marginal model improvement with lower RMSEA (0.05) and SRMR (0.04) and AIC (1734.5917) values, but with the CFI (0.89) and NNFI (0.88) being still lower than the threshold value of $>0.90$.

Inspection of the modified four-factor solution model showed that although the influential coping subscale had a strong loading (0.87) onto the overall PCBI construct, its loading was the lowest in comparison with the other three subfactors (>0.94). The influential coping subscale also had the lowest correlations with the other three factors and overall PCBI scale (see Table 2). It was therefore decided to exclude the 5 -item influential coping subscale in order to improve the model fit of the PCBI. This step reduced the modified 39-item PCBI to only 34 items.

The third CFA model (34 items) involved calculating a three-factor CFA solution (items of the three PCBI factors inventive coping behaviour, engaging coping behaviour and intentional coping behaviour - loading onto the three factors, and the three factors loading onto the overall PCBI construct - see Table 4). As shown in Table 3, the three-factor CFA solution showed model improvement and good model fit $($ lower $\mathrm{AIC}=1429.5063 ; \mathrm{CFI}=0.92$ and $\mathrm{NNFI}=0.90$; RMSEA $=0.05$ and SRMR $=0.04)$. Table 4 shows that all path coefficients were significant $(t>2.56 ; p \leq 0.01)$ and above the threshold value of 0.50 . These results provided evidence of the structural (convergent) validity of the three-factor CFA solution of the PCBI. Analysis of the internal reliability coefficients of the three-factor model revealed high reliability coefficients: inventive coping: $\alpha=0.83 / \mathrm{CR}=0.88$; engaging coping behaviour: $\alpha=0.87 / \mathrm{CR}=0.91$; intentional coping behaviour: $\alpha=0.93 / \mathrm{CR}=0.95$; and overall PCBI: $\alpha=0.95 / \mathrm{CR}=0.96$.

Closer inspection of Table 4 revealed that the inventive coping behaviour sub-dimension retained eight items relating to positive psychology constructs such as wisdom, self-esteem, optimism, humour, locus of control, openness to experience and positive reframing. The eight items of the engaging coping behaviour factor related to positive coping constructs such as positive affect, emotional granularity, happiness and self-efficacy. The 18 items of the intentional coping behaviour sub-dimension related to positive coping constructs such as self-efficacy, resilience, flourishing, intention for positive health, proactive behaviour, conscientiousness and adaptability.

\section{Discussion}

The present research contributed to the positive coping behaviour literature and research by examining the construct validity of a multidimensional scale that was developed to measure positive coping behaviour in the South African organisational context. Overall, the PCBI showed satisfactory internal structural validity and can be regarded as a reliable and useful multidimensional measure of positive psychology 
TABLE 3: Positive coping behavioural inventory model fit statistics: Competing measurement models.

\begin{tabular}{lccccc}
\hline Model & Chi-square/df & RMSEA & SRMR & CFI & NNFI \\
\hline One-factor CFA model & $4.24^{*}$ & 0.08 & 0.06 & 0.77 & 0.75 \\
Original four-factor CFA model & $2.83^{*}$ & 0.06 & 0.05 & 0.88 & 0.87 \\
Modified four-factor CFA model & $2.89^{*}$ & 0.05 & 0.04 & 0.89 & 0.87 .1523 \\
Three-factor CFA model & $2.48 *$ & 0.05 & 0.04 & 0.92 & 0.90 \\
\hline
\end{tabular}

CFA, confirmatory factor analysis; df, degrees of freedom; RMSEA, root mean square error of approximation; SRMR, standardised root mean square; CFI, comparative fit index; NNFI, non-normed fit index; AIC, Akaike Information Criterion.

$N=525$.

$*, p \leq 0.0001$.

TABLE 4: Standardised path coefficients for the three-factor structural model data.

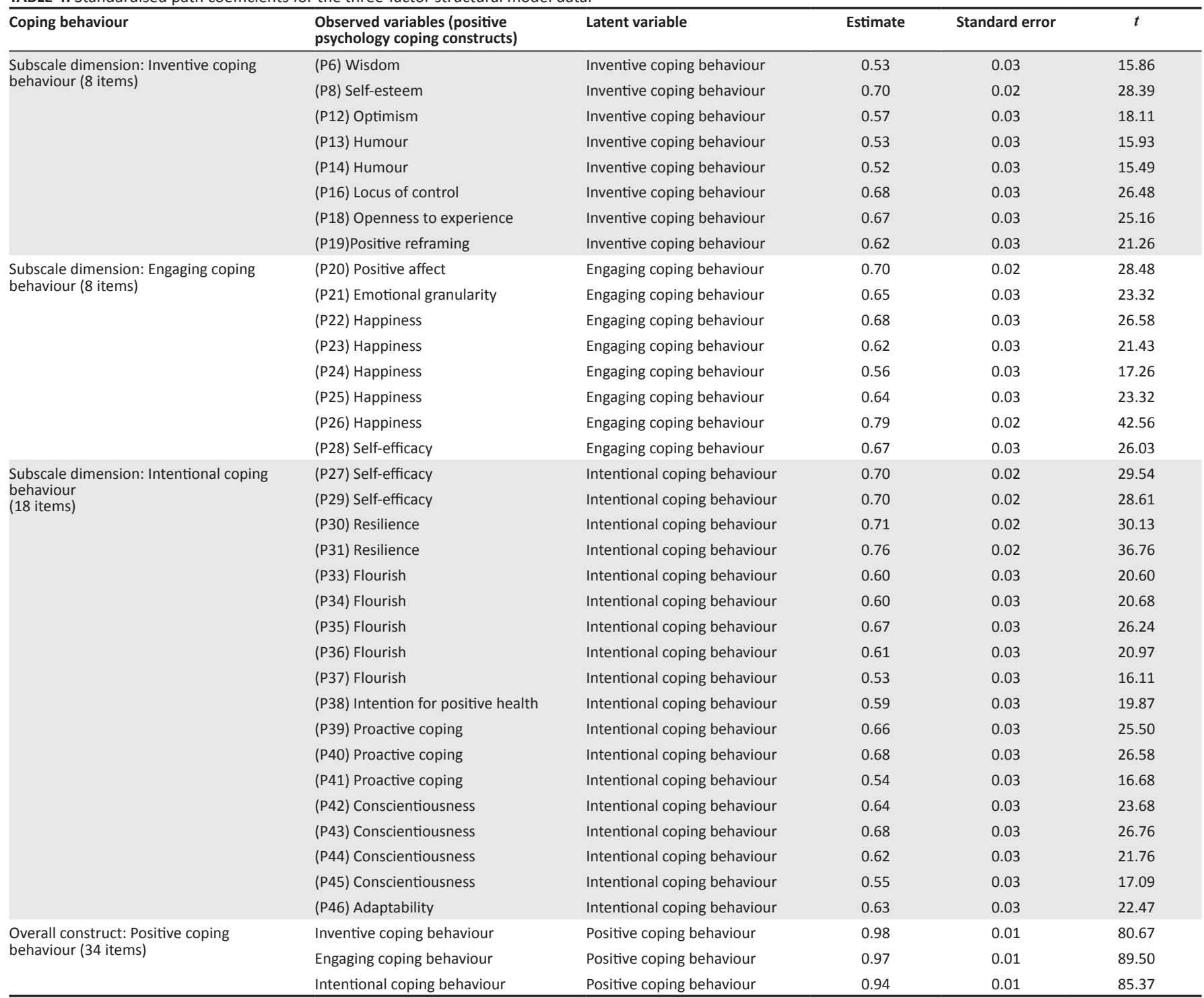

$n=52$.

$\mathrm{P}$, original positive coping behavioural inventory item.

$t$-values $>2.56(p \leq 0.01) ; t$-values $>1.96(p \leq 0.05)$.

constructs. The study extended the findings of the initial EFA conducted by Marx (2016) on the PCBI by providing evidence of the structural improvement of the scale if only three factors (34 items) are retained. The three-factor solution (inventive coping behaviour, engaging coping behaviour and intentional coping behaviour) had evidence of internal construct (convergent and structural) validity. Inspection of the path coefficients revealed that each item demonstrated convergent validity in that each item had a salient loading $(>0.50)$ on its theoretically intended factor. Similarly, the three factors had convergent validity in that each factor had a salient loading $(>0.50)$ on the overall PCBI factor. However, future crossvalidation studies should examine the external construct (convergent and discriminant) validity of the PCBI in relation to other scales that measure positive psychology constructs. The cognitive (inventive problem-solving coping behaviour), emotional (engaging coping behaviour) and social (influential coping behaviour) dimensions compare well with Hammer's (1988) CRI. Future studies on the structural validity of the PCBI in relation to the CRI may be useful to further validate the PCBI. 
Comparing the one-factor CFA model with the initial fourfactor solution also provided initial evidence of the internal discriminant validity of the PCBI. However, the somewhat low AVE values indicated the presence of measurement error, which could potentially negatively influence the discriminant validity of the PCBI. Although the bivariate correlations were below $r<0.80$, the correlations among the three constructs were high $(r>0.70)$, which could allude to concerns about internal divergent (discriminant) validity. AVE values above 0.50 and correlations of 0.60 and less are generally interpreted as providing support for discriminant validity (Kline, 2011).

The current results suggest that the PCBI may be a useful and reliable alternative to other internationally developed measures of positive psychology constructs in the workplace. The contribution made by the PCBI alludes to the scale developer's effort to integrate the measurement of a wide array of positive psychology constructs into a single multidimensional measure. This feature of the PCBI points to further research on the psychometric properties of the PCBI as being a worthwhile endeavour that could extend the assessment of positive psychology behaviour in the South African organisational context in a cost-effective manner. Future research in various organisational settings with occupational and socio-demographic diverse groups should therefore further investigate the external construct (convergent and discriminant) validity of the PCBI in relation to other scales measuring similar positive psychology constructs. Examples of such scales include (but are not limited to) the assessing emotions scale (Schutte et al., 1998), PsyCap scale (PCQ-24: Luthans et al., 2007), the psychological well-being scale (Ryff, 1989), measure of optimism (Scheier \& Carver, 1985), resilience scale (Wagnild \& Young, 1993), selfefficacy measure (Parker, 1998), psychosocial flourishing scale (Diener et al., 2010), the basic traits inventory (Taylor \& De Bruin, 2006) and the locus of control scales (e.g. Schepers, 2005). These scales measure positive psychology constructs also evident in the PCBI such as optimism, self-efficacy, selfacceptance, resilience, adaptability, emotional intelligence, locus of control, flourishing, openness to experience and conscientiousness. Heterotrait-monotrait procedures (Henseler, Ringle \& Sarstedt, 2015) could be utilised to provide estimates of external convergent and divergent validity of the PCBI. Future studies may also provide opportunity for further refinement of the structural and construct validity of the PCBI. Another advantage of the PCBI is that the scale has been developed and tested in the multiculturally diverse South African organisational context. It is recommended that future studies also examine the structural equivalence of the PCBI for age, gender and ethnicity groups to ensure bias-free assessment of positive coping behaviour in the South African workplace.

\section{Research limitations}

Because of the cross-sectional design of the research, the results cannot be generalised to other industry settings. It is therefore imperative that the study be replicated in relation to other measures of positive psychology construct measures across a wider, more representative South African sample in various industry settings. The low AVE values indicated the presence of measurement error, which was not further investigated in the study. Consideration of confounding factors that could influence self-report measures such as the PCBI and therefore contribute to measurement error should be incorporated in future research endeavours.

\section{Conclusion}

This study contributed to the emerging body of knowledge on the assessment of positive psychology constructs that contribute to employees' well-being and flourishing in the South African workplace. The results provide preliminary evidence of the usefulness of the PCBI as a valid and reliable multidimensional measure that integrates a wide array of positive psychology attributes in a single measure. The convergent validity of the PCBI as a measure of three higherorder dimensions of positive coping behaviour (inventive, engaging and intentional coping behaviours) was demonstrated in this study. Researchers may confidently use the three-factor solution of the PCBI to measure employees' self-evaluations of their capacity to demonstrate positive coping behaviour in the workplace.

\section{Acknowledgements Competing interests}

The authors declare that they have no financial or personal relationship(s) that may have inappropriately influenced them in writing this article.

\section{Authors' contributions}

M.C. conducted the data analysis and wrote up the research article. A.A.M. collected the data and contributed to the literature review. I.L.P. contributed to the literature review.

\section{References}

Alarcón, D., \& Sánchez, J.A. (2015). Assessing convergent and discriminant validity in the ADHD-R IV rating scale. Spanish STATA Meeting, October 22, 2015, University of Pablo de Olavide, Seville, Spain.

Ardelt, M., \& Edwards, C.A. (2015). Wisdom at the end of life: An analysis of mediating and moderating relations between wisdom and subjective well-being. The Journals of Gerontology, 71(3), 502-513. https://doi.org/10.1093/geronb/gbv051

Asamani, L., Cobbold, C., \& Dai-Kosi, A.D. (2015). Career orientations as antecedent of perceived life satisfaction among Ghanaian teachers. Public Policy and Administration Research, 5(4), 84-94.

Demerouti, E., \& Bakker, A.B. (2011). The Job Demands-Resources model: Challenges for future research. South African Journal of Industrial Psychology, 37(2), Art. \#974, 1-9. https://doi.org/10.4102/sajip.v37i2.974

Diener, E., Wirtz, D., Tov, W., Kim-Prieto, C., Choi, D., Oishi, S., et al. (2010). New wellbeing measures: Short scales to assess flourishing and positive and negative feelings. Social Indicators Research, 97(2), 143-156. https://doi.org/10.1007/ s11205-009-9493-y

De Zutter, J., Luyck, K., Schaap-Jonker, H., Büssing, A., Corveleyn, J., \& Hutsebaut, D. (2010). God image and happiness in chronic pain patients: The mediating role of disease interpretation. Pain Medicine, 11(5), 765-773. https://doi.org/10.1111/ j.1526-4637.2010.00827.x

Employment Equity Act (Act No. 55 of 1998). Pretoria. Government Printer.

Fornell, C., \& Larcker, D.F. (1981). Evaluating structural equation models with unobservable variables and measurement error. Journal of Marketing Research, 1, 39-50. https://doi.org/10.2307/3151312

Fornés-Vives, J., Garcia-Banda, G., Frias-Navarro, D., \& Rosales-Viladrich, G. (2015) Coping, stress, and personality in Spanish nursing students: A longitudinal study. Nurse Education Today, 36, 318-323. https://doi.org/10.1016/j.nedt.2015.08.011 
Görgens-Ekermans, G. \& Herbert, M. (2013). Psychological capital: Internal and external validity of the Psychological Capital Questionnaire (PCQ-24) on a South African sample. South African Journal of Industrial Psychology, 39(2), Art.\#1131 African sample. South African Journal of Industrial
1-12. https://doi.org/10.4102/sajip.v39i2.1131

Hair, J.F., Black, W.C., Babin, B.J., \& Anderson, R.E. (2010). Multivariate data analysis. (7th edn.). London: Pearson Prentice-Hall.

Hammer, A.L. (1988). Manual for the coping resources inventory. Palo Alto, CA Consulting Psychologists Press.

Helmer, S.M., Krämer, A., \& Mikolajczyk, R.T. (2012). Health-related locus of control and health behaviour among university students in North Rhine Westphalia, Germany. BMC Research Notes, 5(1), 703-115. https://doi.org/10.1186/1756-0500-5-703

Henseler, J., Ringle, C.M., \& Sarstedt, M. (2015). A new criterion for assessing discriminant validity in variance-based structural equation modeling. Journal of the Academy of Marketing Science, 1, 1-21. https://doi.org/10.1007/s11747-014-0403-8

Hu, L., \& Bentler, P.M. (1999). Covariance structure analysis: Conventional criteria versus new alternatives. Structural Equation Modeling, 6(1), 1-55. https://doi. org/10.1080/10705519909540118

Keyes, C.L.M. (2002). The mental health continuum: From languishing to flourishing in life. Journal of Health and Social Behavior, 43, 207-222. https://doi.org/ $10.2307 / 3090197$

Keyes, C.L.M., \& Annas, J. (2009). Feeling good and functioning well: Distinctive concepts in ancient philosophy and contemporary science. Journal of Positive Psychology, 4, 197-201. https://doi.org/10.1080/17439760902844228

Kim, B.H., Newton, R.A., Sachs, M.L., Glutting, J.J., \& Glanz, K. (2012). Effect of guided relaxation and imagery on falls self-efficacy: A randomized controlled trial. JAGS, 60, 1109-1114. https://doi.org/10.1111/j.1532-5415.2012.03959.x

Kleiman, E.M., \& Riskind, J.H. (2012). Utilized social support and self-esteem mediate the relationship between perceived social support and suicide ideation. Crisis, 34(1), 42-49. https://doi.org/10.1027/0227-5910/a000159

Kline, R.B. (2011). Principles and practice of structural equation modeling. New York: Guilford Press.

Lambert, N.M., Graham, S.M., Fincham, F.D. \& Stillman, T.F. (2009). A changed perspective: How gratitude can affect sense of coherence through positive perspective: How gratitude can affect sense of coherence through positive
reframing. The Journal of Positive Psychology, 4(6), 461-470. https://doi.org/ reframing. The Journal of Positiv

Lucas, R.E., \& Fujita, F. (2000). Factors influencing the relation between extraversion and pleasant affect. Journal of Personality and Social Psychology, 79, 1039-1056. https://doi.org/10.1037/0022-3514.79.6.1039

Luthans, F., Avolio, B.J., Avey, J.B., \& Norman, S.M. (2007). Positive psychological capital: Measurement and relationships with performance and satisfaction. Personne Psychology, 60(3), 541-572. https://doi.org/10.1111/j.1744-6570.2007.00083.x

Marx, A.A. (2016). Development of the Positive Coping Behavioural Inventory: A positive psychological approach. Unpublished doctoral thesis, University of South Africa, Pretoria, South Africa.

Mayer, C.H. (2014). Sense of coherence and professional career development. In M Coetzee (ed.), Psycho-social career meta-capacities: Dynamics of contemporary career development (pp. 221-246). Dordrecht: Springer International.

McGraw, A.P., Warren, C., \& Kan, C. (2015). Humorous complaining. Journal of Consumer Research, 41(5), 1153-1171. https://doi.org/10.1086/678904

Metzer, A.A., De Bruin, G.P., \& Adams, B.G. (2014). Examining the construct validity of the Basic Traits Inventory and the ten-item Personality Inventory in the South African context. South African Journal of Industrial Psychology, 40(1), Art.\#1005, African context. South African Journal of Industr
$1-9$. https://doi.org/10.4102/sajip.v40i1.1005

Ong, F.S., Phillips, D.R., \& Chai, S.T. (2013). Life events and stress: Do older men and women in Malaysia cope differently as consumers? Journal Cross Culture Gerontology, 28, 195-210. https://doi.org/10.1007/s10823-013-9190-9

Papastavrou, E., Tsangari, H., Karayiannis, G., Papacostas, S., Efstathiou, G., \& Sourtzi, P. (2011). Caring and coping: The dementia caregivers. Aging \& Mental Health, 15(6), 702-711. https://doi.org/10.1080/13607863.2011.562178
Parker, S. (1998). Enhancing role-breadth self-efficacy: The roles of job enrichment and other organizational interventions. Journal of Applied Psychology 83, 835-852. https://doi.org/10.1037/0021-9010.83.6.835

Proyer, R.T., Gander, F., Wellenzohn, S., \& Ruch, W. (2014). Positive psychology interventions in people aged 50-79 years: Long-term effects of placebo-controlled online interventions on well-being and depression. Aging \& Mental Health, 18(8), 997-1005. https://doi.org/10.1080/13607863.2014.899978

Rothmann, S. (2014). Flourishing in work and careers. In M. Coetzee (ed.), Psychosocial career meta-capacities: Dynamics of contemporary career development (pp. 203-220). Dordrecht: Springer International. https://doi.org/10.1007/978-3319-00645-1 11

Ryff, C.D. (1989). Happiness is everything, or is it? Explorations on the meaning of psychological well-being. Journal of Personality and Social Psychology, 57, 1069-1081. https://doi.org/10.1037/0022-3514.57.6.1069

Ryff, C.D. \& Keyes, C.L.M. (1995). The structure of psychological well-being revisited. Journal of Personality and Social Psychology, 69, 719-727. https://doi. org/10.1037/0022-3514.69.4.719

SAS. (2013). Statistical Analysis System, Version 6.1. Cary, NC: SAS Institute.

Scheier, M.F. \& Carver, C.S. (1985). Learned optimism. New York: Knopf.

Schepers, J.M. (2005). The construction of a normative scale of locus of control. South African Journal of Industrial Psychology, 31(3), 1-11. https://doi.org/10.4102/ sajip.v31i3.201

Schutte, N., Malouff, J., Hall, E., Haggerty, D., Cooper, J., Golden, D., \& Dornheim, L. (1998). Development and validation of a measure of emotional intelligence. Personality and Individual Differences, 25, 167-177. https://doi.org/10.1016/ Personality and Individual

Serena, K. (2013). Occupational stress, psychological capital, happiness and turnover intentions among teachers. Unpublished doctoral thesis. University of KwaZuluNatal, Durban.

Sims, T., Hogan, C.L., \& Carstensen, L.L. (2015). Selectivity as an emotion regulation strategy: Lessons from older adults. Current Opinion in Psychology, 3, 80-84. https://doi.org/10.1016/j.copsyc.2015.02.012

Snyder, C.R., Lopez, S.J., \& Pedrotti, J.T. (2011). Positive psychology. The scientific and practical explorations of human strengths. (2nd edn.). Thousand Oaks, CA: Sage.

Stratta, P., Capanna, C., Dell'Osso, L., Carmassi, C., Patriarca, S., Di Emidio, G., \& Rossi, A. (2015). Resilience and coping in trauma spectrum symptoms prediction: A structural equation modeling approach. Personality and Individual Differences, 77, 55-61. https://doi.org/10.1016/j.paid.2014.12.035

Sulea, C., van Beek, I., Sarbescu, P., Virga, D., \& Schaufeli, W.B. (2015). Engagement, boredom, and burnout among students: Basic need satisfaction matters more than personality traits. Learning and Individual Differences, 42, 132-138. https:// doi.org/10.1016/j.lindif.2015.08.018

Taylor, N. \& De Bruin, G.P. (2006). BTI. Johannesburg, South Africa: Manual of the Basic Traits Inventory, JVR.

Van der Heijde, C.M. (2014). Employability and self-regulation in contemporary careers. In M. Coetzee (ed.), Psycho-social career meta-capacities: Dynamics of contemporary career development (pp. 7-18). Dordrecht: Springer International.

Wagnild, G.M., \& Young, H.M. (1993). Development and psychometric evaluation of the resiliency scale. Journal of Nursing Management, 1(2), 165-178.

Windle, G. (2011). What is resilience? A review and concept analysis. Reviews in Clinical Gerontology, 21(2), 152-169. https://doi.org/10.1017/S0959259810000420

Youssef, C.M., \& Luthans, F. (2012). Positive global leadership. Journal of World Business, 47, 539-547. https://doi.org/10.1016/j.jwb.2012.01.007

Zhao, H., \& Seibert, S.E. (2006). The big five personality dimensions and entrepreneurial status: A meta-analytical review. Journal of Applied Psychology, 91(2), 259-271. https://doi.org/10.1037/0021-9010.91.2.259 